\title{
Research on Effective Implementation Strategy of Management Accounting Informationization under Financial Shared Service Mode
}

\section{Fen Cheng}

\author{
Chongqing College of Chemical Engineering, Chongqing, 400020, China
}

Keywords: Financial Sharing Service; Management Accounting Informationization; Necessity; Implementation Strategy

\begin{abstract}
The traditional accounting treatment method is heavy and inefficient, and it is difficult to meet the needs of the development of the times. The management accounting informationization under the financial sharing service has become a trend. This paper starts from the two aspects of improving the quality of enterprise management accounting and improving the accuracy of financial data processing. It analyzes the role of management accounting informationization under financial sharing service, and based on this, proposes management accounting information under financial sharing service, implements the strategy, and then provides some reference and help for relevant researchers.
\end{abstract}

\section{Introduction}

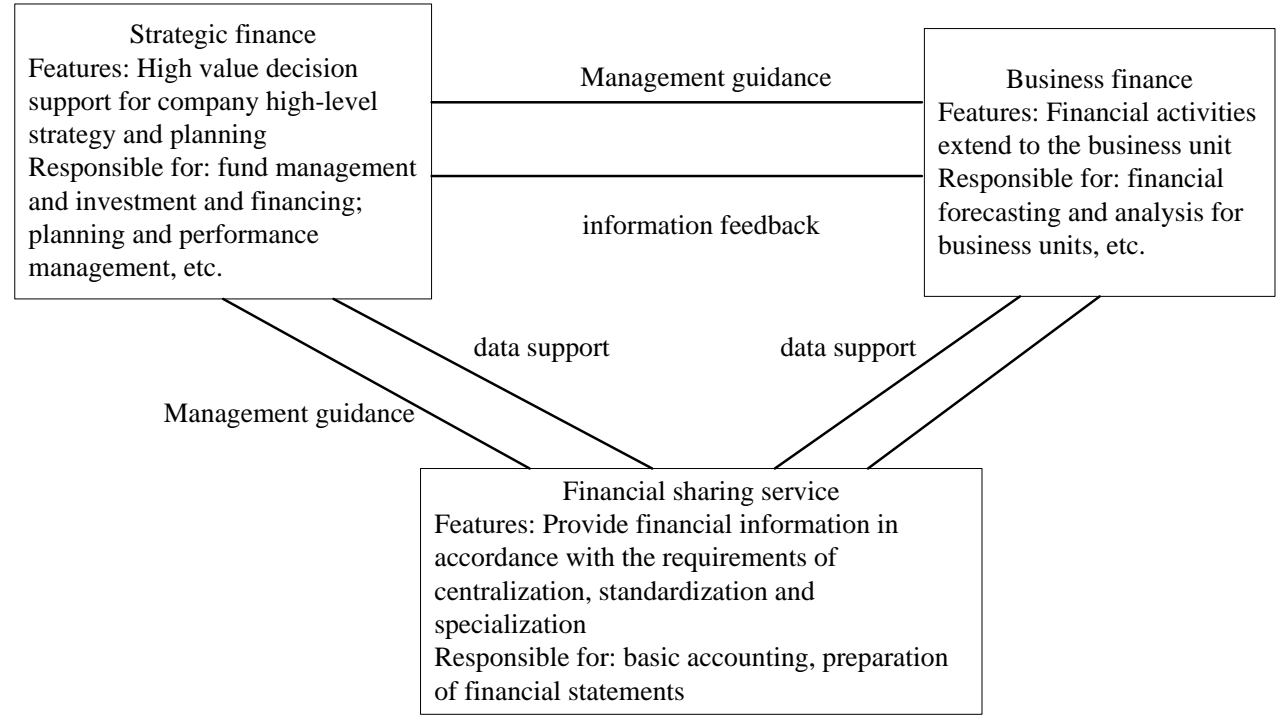

Fig 1. Typical financial sharing strategic relationship

With the continuous improvement of the market economy, it has promoted the rapid development of the accounting industry and achieved good results. In the process of development, the management accounting has achieved certain results. The traditional working methods can no longer meet the needs of the information society [1-3]. At present, most enterprises have begun to implement financial sharing services, using computers instead of manual financial management. The modern scientific and technological achievements have changed the management accounting work methods, making the management work more convenient, ensuring the quality and greatly improving the work efficiency, and promoting the further development of management accounting. However, the relevant data shows that there is still a way to go to establish and improve the management accounting informationization under the financial sharing service. It has different depth problems at different levels. On the micro level, it affects the construction of management accounting informationization. And development, macroscopically it affects the sustainable 
development of China's economy [4]. It is necessary to use information technology to promote the economic efficiency of enterprises. In order to make financial sharing services better applied to enterprise management, we should promote the continuous improvement of the level of informatization and make it play an important role in the development of enterprises. Therefore, in the process of discussing management accounting informationization, it should be based on financial sharing, which is conducive to expanding the scope of accounting informationization, promoting the speed of information development, improving the management level of enterprises, and typical financial sharing strategy. The relationship is shown in Figure 1.

\section{The necessity of management accounting informationization under financial sharing service}

(1) Improve the quality of enterprise management accounting. From the perspective of enterprise operation and management, the original accounting treatment method generally relies on manpower or more complicated accounting methods to achieve the effect of managing financial information and data, as shown in Figure 2. With the original financial management approach, the exploration and evaluation of corporate financial data and information can be achieved. However, the current role of the company in implementing financial management is to use the company's operating conditions and financial data. In addition to processing the relevant data, the results can be explored to predict and evaluate the future development and operation of the company. With the help of modern computing methods and management facilities, financial data can be transmitted in the system. Based on real financial statistics, computer technology can be used to explore all financial data of the enterprise, thereby improving the authenticity and accuracy of financial data processing results. In addition, computer data can be used to realize the refinement and exploration of financial data. Under the influence of computer facilities, not only can the authenticity of data processing results be improved, but also the rigor of data processing can be ensured [5]. The improvement of the quality of corporate management accounting.

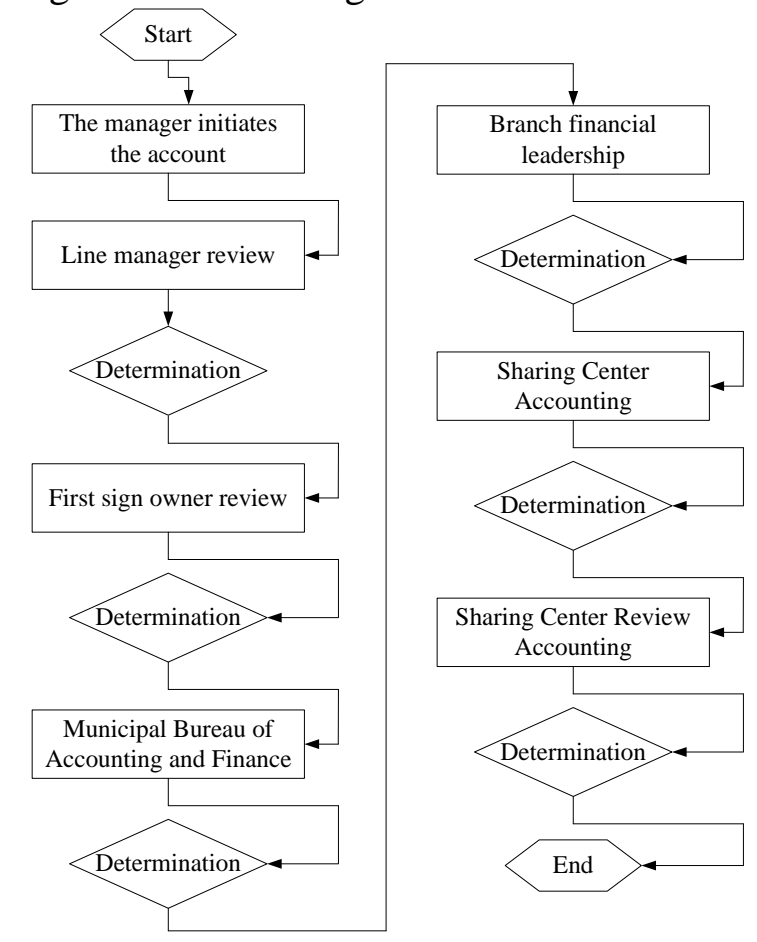

Fig.2 Accounting process for general accounting matters

(2) Improve the accuracy of financial data processing. Combining with the investigation of the original financial data processing, we learned that the financial data is not accurate as the main loophole in the original management accounting, and further exploration, the basis for processing all economic and financial information of the enterprise can be found. The fundamental factor that 
leads to the problem of management quality is the lack of a sound enterprise economic management system. Assuming that the company lacks a sound management system, it will not be able to regulate and standardize the work behavior of management accounting staff.In addition, the company can not get the effect of scientific processing in the process of exploring the financial statements, which in turn makes the overall financial management level of the enterprise low. The integration of information technology into management accounting can make use of a sound information management system to regulate the financial work behavior of enterprises, and it can also promote the implementation and development of financial work. Under the background of informationization, the management system can provide conditions for the scope and role of management accounting duties. Under the conditions of implementing financial data exploration, financial facilities can be used to organize and process financial work, thereby improving the accuracy of financial data processing results.

Below, this paper will further elaborate and analyze the management accounting informationization implementation strategy under the financial sharing service. In turn, it provides some reference and help for relevant researchers.

\section{Implementation strategy of management accounting informationization under financial sharing service}

(1) Safeguarding the security of accounting information. The security of information security is the premise of management accounting informationization under financial sharing service. To promote the improvement of accounting information quality, it is necessary to ensure the security of accounting information and promote the safe implementation of accounting informationization. On the basis of information, with the help of information technology of corporate financial information, promote the improvement of enterprise performance evaluation system, carry out comprehensive budget or cost control within the enterprise, realize the control of financial management information of enterprises, and promote the finance of enterprises. Safe operation, promote the company to achieve good economic benefits, in order to create greater economic benefits for the enterprise. In the process of using the financial sharing information system, it mainly promotes the effective development of enterprise informationization by means of the financial data of the enterprise and the content between related clients, establishes the foundation for the effective implementation of enterprise information, and ensures the security of the financial information of the enterprise. Stability, promote the effective implementation of corporate financial information. The specific aspects should be combined with the following aspects. It is necessary to strengthen the management of corporate customers, and the behavior of some users should be stopped, and combined with the actual application, reasonable suggestions should be put forward to ensure the smooth development of various financial work. When training employees of the company, the behavior of the users should be monitored, and the illegal activities should be stopped in time.

(2) Applying big data theory to management accounting. The application of big data theory is an important means of management accounting informationization under the financial sharing service. With the advent of the big data era, it has promoted the transformation of corporate financial accounting management mode, which brings both opportunities and challenges to accountants. The current financial information is being reformed. Most enterprises face more financial problems in the process of financial information management. As the actual development process of the enterprise, the employees often face the situation that the bill information cannot be difficult to distinguish. According to the analysis of the enterprise big data, the enterprise In the process of financial data analysis and statistics, managers should combine the knowledge of enterprise financial data to identify the increase of financial information of enterprises and realize the analysis of financial indicators of enterprises. Therefore, in financial management accounting, we should rely on the advantages of the big data information platform to provide accurate information for the development of financial information of enterprises, and to achieve predictions and decisions on various economic activities of enterprises. Therefore, in the process of enterprise management operation, big data should analyze the enterprise data effectively, realize the rapid understanding of 
enterprise accounting information, promote the effective combination of big data and financial information, and lay a good foundation for the financial informationization of enterprises.

(3) Strengthen the training of accounting information management talents. Talent is the foundation of management accounting informationization under financial sharing service. The financial shared service center is a technology that conveys high construction efficiency and reduces the cost of the whole operation process. It is a reason for improving the efficiency of accounting work, and more financial accounting personnel are facing The problem is the transition from auditing to management. In order to promote the effective implementation of corporate financial information, it is necessary to conduct regular training for employees. At present, the composition of financial personnel is imbalanced in the composition of most enterprises. The professional qualifications of accounting personnel are not in line with the current financial development needs of enterprises. There are relatively many traditional accounting personnel, and the use of accounting personnel is relatively scarce. In the process of training enterprise financial personnel, we should combine the financial data information and financial technology of the enterprise to carry out regular training work for financial personnel, strengthen the professional quality of the employees, and improve the professional competence of the financial personnel. In the process of implementing corporate financial work, the professional competence of employees is an important factor in improving the financial management level of enterprises. Financial data plays an important role in the enterprise financial information management system. Relevant financial personnel need to reasonably process and process the data so as to provide reliable financial information for the decision makers of the enterprise and accelerate the understanding of the financial information of the enterprise. Therefore, strengthening the training of enterprise financial personnel accounting information management is the key content of current financial management of enterprises. It should change the role of financial personnel so that financial personnel can master professional financial information and realize the maintenance of enterprise financial information system.

(4) Broaden the service level of management accounting. Service level is the guarantee of management accounting informationization under financial sharing service. Accounting informationization is widely used in current enterprise financial management work, which can play a good financial effect and become an important part of corporate financial information. Usually in the financial information management process of the enterprise, there are often cases where the financial sharing service is separated from the various departments of the enterprise. To solve this problem, the distance in the customer service area is required to improve the quality of service for the purpose of better. Promote the efficiency of business work. In the actual application process, it should combine the advantages of current network information and Internet technology to promote the improvement of information technology, ensure the effective implementation of corporate financial management, and ensure the effective implementation of corporate financial accounting. At present, the main information systems of enterprises include: ERP system and online banking system, which is conducive to promoting the interconnection system of enterprises. In the reporting section of enterprises, comprehensive coverage of the entire information should be realized, and the advantages of the information system should be fully grasped. It can promote the improvement of management accounting level, promote the reduction of corporate financial costs, and reduce the financial risks of enterprises.

(5) Strengthen the application of cloud computing in financial sharing. Cloud computing is an important support for management accounting informationization under financial sharing services. The common cloud computing sharing model is shown in Figure 3. In the application process of enterprise financial accounting, cloud computing is widely used in the accounting information system of enterprises as a kind of advanced technology. In the process of application, it should be better combined with the advantages of corporate financial accounting. Among the financial sharing services. First of all, through the use of cloud computing, the cost of enterprise informationization can be effectively reduced. Before use, the information in the cloud computing platform should be integrated into the financial sharing information. By purchasing the cloud computing server in 
advance, according to the actual The situation pays a certain fee, realizes the maintenance of the financial shared information system, and prevents the expenditure of cost information. Secondly, in order to effectively cooperate with each other, in the process of enterprise development, the quality of accounting informationization should be improved, the sharing of accounting information should be realized, and the related financial business should be combined to increase the support for corporate strategic decision-making and promote The improvement of corporate financial synergies. Finally, we should improve the professional quality and efficiency of corporate finance personnel, implement a financial sharing system within the enterprise, and apply cloud computing to management informationization. This is also a new development trend in the next few decades.

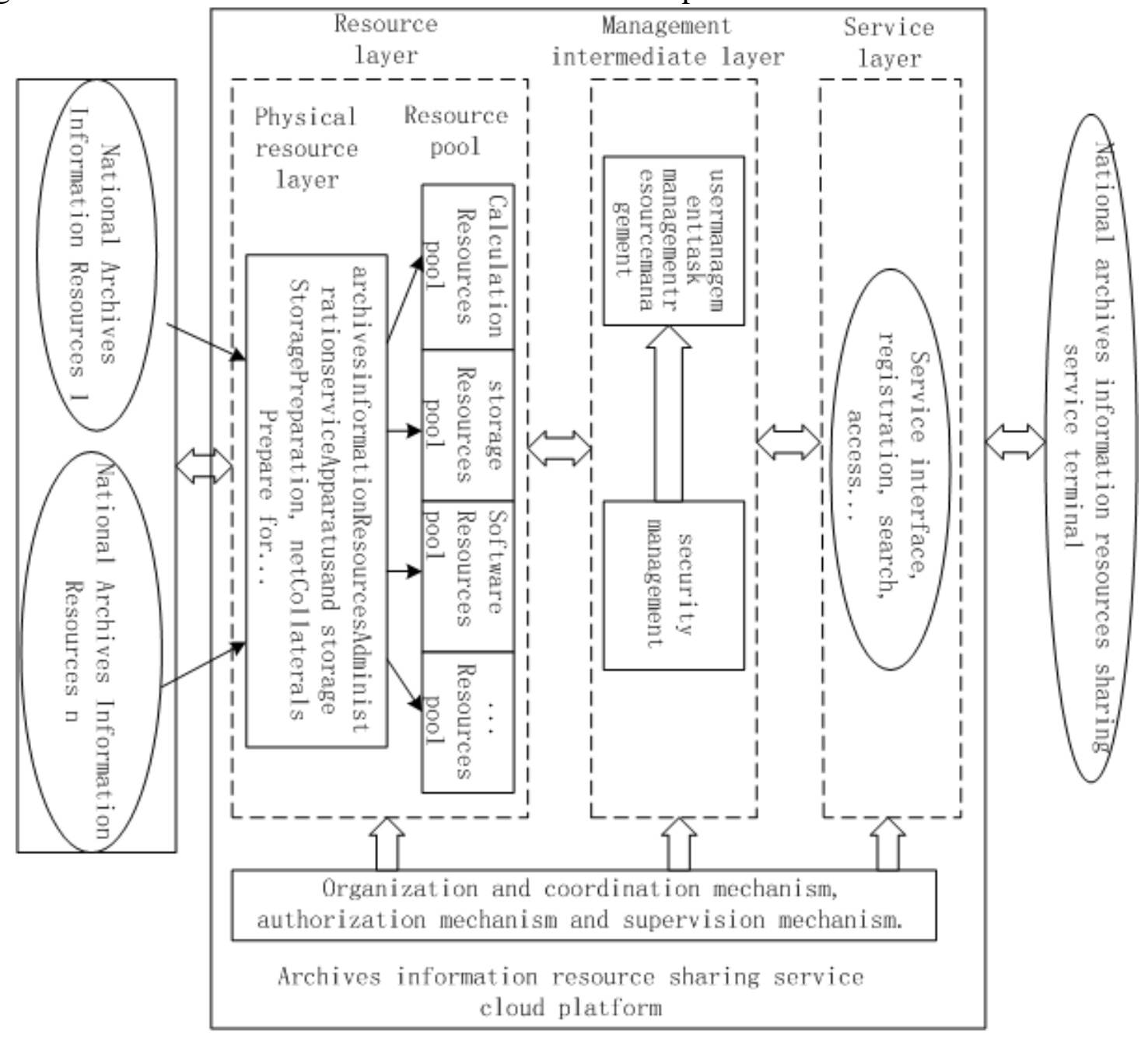

Fig. 3 Cloud computing sharing mode

\section{Conclusion}

In the process of financial management of enterprises, it is necessary to adhere to the service of financial sharing, promote the optimization of financial information of enterprises, and play a positive role in promoting the development of enterprises. In the process of implementation, enterprise management accounting should combine the characteristics of enterprises and learn from domestic and foreign practical experience to achieve effective integration of corporate financial information, promote the improvement of corporate financial information, and ensure that corporate financial information can be oriented toward the development of accounting information. Make progress. Therefore, we must improve the financial management information of the enterprise, improve the internal financial management system, and enhance the core competitiveness of the enterprise. 


\section{References}

[1] Xie Rongjuan. Implementation Strategy of Management Accounting Informationization under Financial Sharing Service [J]. Enterprise Reform and Management, 2018(5): 157-158.DOI: 10.13768/j.cnki.cn11-3793/f.2018.0632.

[2] Gu Xunhui. Analysis of effective implementation strategy of management accounting informationization under financial sharing service [J]. China Management Information, 2017(24): 43-44. DOI:10.3969/j.issn.1673 - 0194.2017. 24.026 .

[3] Liu Zhenwei. Effective Implementation of Management Accounting Informationization Based on Financial Shared Services [J]. China Management Informationization, 2018, (7): 64-65.DOI: 10. 3969/j. issn. 1673 - 0194. 2018. 07. 027.

[4] Feng Juan. Analysis of Effective Implementation Strategy of Management Accounting Informationization under Financial Sharing Service [J]. Economic and Trade Practice, 2017(24): 255.DOI: 10.3969/j.issn.1673 - 0194.2017.24.026.

[5] Wei Yaoqin. Discussion on Effective Implementation Strategy of Management Accounting Informationization under Financial Sharing Service [J]. Finance and Economics (Academic Edition), 2015(20):211-211.DOI:10.3969/j.issn.1009- 2781.2015.30.185 . 